\title{
Los medios de comunicación entre la regulación y la libertad: el falso dilema vivido por Brasil en los treinta años de su constitución*
}

\author{
Gustavo Ferreira Santos ${ }^{a}$
}

\begin{abstract}
Resumen: La Constitución brasileña de 1988 trajo un conjunto de principios y reglas sobre la comunicación social. Sin embargo, no hubo un desarrollo legislativo de los temas tratados en el texto constitucional. El presente trabajo discute la ausencia de regulación legislativa, evidente a pesar de la existencia de parámetros constitucionales adecuados. Para ello, hace una presentación de los dispositivos del capítulo de la Constitución que trata el tema y, por otra parte, estudia una iniciativa legislativa popular, que aún está en fase de discusión en la sociedad civil. Como un ejercicio previo a dicho análisis, discute la complejidad de la relación entre medios y derechos fundamentales y las justificaciones para una actuación regulatoria estatal.
\end{abstract}

Palabras clave: medios; democracia; regulación; libertad de expresión

Fecha de recepción: 10 de noviembre de 2018 Fecha de evaluación: 28 de mayo de 2019

Fecha de aprobación: 4 de junio de 2019

Cómo citar: Ferreira Santos G. (2019). Los medios de comunicación entre la regulación y la libertad: el falso dilema vivido por Brasil en los treinta años de su constitución. Revista Prolegómenos, 22(44), pp. 83-96. DOI: https://doi.org/10.18359/prole.3461

* Este trabajo es elaborado en el contexto de la investigación "A proteção multinível da expressão e da comunicação" (cNPq n. 311020/2015-1), en la Universidad Católica de Pernambuco.

a Mestre (UFSC) y Doctor (UFPE) en Derecho. Profesor de Derecho Constitucional de la Universidad Católica de Pernambuco, en Brasil. Becario de Productividad en Investigación, del CNPq-Consejo Nacional de Desarrollo Científico y Tecnológico, en Brasil. 


\title{
The Media Amidst Regulation and Freedom: The False Dilemma Experienced by Brazil in the Thirty Years of Its Constitution
}

\begin{abstract}
The 1988 Brazilian Constitution brought a set of principles and rules on social communication. However, there was no legislative elaboration of the matters discussed in the constitutional text. This paper discusses the absence of legislative regulation, which is noticeable despite the existence of adequate constitutional parameters. For this, it presents the devices contained in the chapter of the Constitution that deals with the subject and studies a popular legislative initiative, which is still being debated by civil society. As an exercise prior to this analysis, it discusses the complex mediafundamental rights relationship and the justifications for a state regulatory action.
\end{abstract}

Keywords: Media; democracy; regulation; freedom of expression

\section{Meios de comunicação entre a regulação e a liberdade: o falso dilema vivenciado pelo Brasil nos trinta anos de sua constituição}

Resumo: A Constituição brasileira de 1988 trouxe um conjunto de princípios e regras de comunicação social. No entanto, não houve desenvolvimento legislativo das questões discutidas no texto constitucional. Este artigo discute a ausência evidente de regulamentação legislativa, apesar da existência de parâmetros constitucionais adequados. Para isso, ele faz uma apresentação dos dispositivos do capítulo da Constituição que trata do assunto e, por outro lado, estuda uma iniciativa legislativa popular, que ainda está em fase de discussão na sociedade civil. Como um exercício prévio a essa análise, a complexidade do relacionamento entre mídia e direitos fundamentais e as justificativas para uma ação reguladora estadual são discutidas.

Palavras-chave: meios; democracia; regulação; liberdade de expressão 


\section{Introducción}

Existe un vínculo innegable entre la comunicación y la democracia. Una decisión popular, en un sistema democrático, no es suficiente apenas en la expresión del voto; es necesario, en consecuencia, que exista una garantía de la forma más amplia posible, para acceder a la información y a las diversas opiniones en cuestión. La decisión individual de apoyar la posición de X o Y necesita estar avalada por un vasto conocimiento de lo que está siendo debatido. En este sentido, hay que tener en cuenta que los medios de comunicación son instrumentos importantes con los que se puede promover o impedir la circulación de la información (Pla, 2001).

A diferencia de la experiencia clásica de la democracia, cuando la comunicación era presencial, o del momento del nacimiento del Estado moderno, cuando los medios eran poco potentes, la radiodifusión, en un primer momento, y la internet, hoy en día, exigen que cambiemos la forma de ver la relación entre comunicación y democracia. Los problemas no giran solo en torno a la libertad individual, sino también a las exigencias de igualdad, de simetría. El Estado juega un papel fundamental como garante de parámetros. Hay varios ámbitos que necesitan el establecimiento de reglas, para proteger derechos o la propia democracia.

En América Latina, la relación entre los medios de comunicación y la democracia siempre estuvo marcada por diversas polémicas. No fueron pocos los casos de apoyo abierto de empresas de comunicación a las dictaduras que asolaron la región en una parte del siglo Xx. Nuevamente establecida la democracia en estos países, la postura política adoptada por una parte considerable de los medios produjo conflictos y denuncias, a causa de la interferencia directa de aquellos en los procesos electorales. La mayor parte de los gobiernos de orientación política de izquierda, que gobernaron algunos países en los últimos años, asumieron una postura política que incluía la regulación de la comunicación social, normalmente fundada en un discurso antimonopolístico.

Las últimas acciones de este conflicto fueron las ediciones de leyes sobre la comunicación social. Argentina creó, en 2009, una ley sobre la radiodifusión que le impuso límites a la titularidad de permisos de transmisión de radio y televisión, garantizando parte del espectro electromagnético, para los canales de entidades sin fines lucrativos. La ley ha sido vista como un modelo de norma para el antiagrupamiento de los medios de comunicación, y elogiada, incluso, por la Relatoría de la ONU para la Libertad y la expresión. Recientemente, ha habido algunos reveses. Infortunadamente, el sistema que la ley creó fue tratado como si fuera solo el acto de un gobierno, pero no una importante acción de Estado. Aquella quedó muy asociada a la imagen de Cristina Kirchner y su regulación fue desestructurada por el Gobierno Macri. Sin embargo, es una experiencia que debe ser analizada. Bolivia y Ecuador han editado igualmente leyes que dividieron su espectro, así como Uruguay, que también editó una nueva ley que regula la radiodifusión.

En ese contexto, cuando la constitución brasileña completa treinta años de vigencia, cabe preguntarse: ¿cómo se encuentra Brasil? ¿De qué forma la Constitución vigente regula la actividad de los medios? ¿Hay algún fundamento constitucional para un posible tratamiento legislativo sobre este asunto? ¿Existen iniciativas en este sentido? En este texto iniciaremos resaltando la compleja protección de los derechos fundamentales frente a los medios, que exige otra mirada sobre la relación entre el Estado y los derechos fundamentales en la comunicación; también demostramos la inexistencia de incompatibilidad entre autorregulación y heterorregulación; luego haremos una descripción del parámetro constitucional de la comunicación; será presentada, además, una visión general sobre la regulación de los medios en la actualidad - o de la inexistencia de dicha regulación-, y se discutirá una iniciativa que tiene partido en la sociedad civil. Así, a partir de una investigación sobre la legislación de los medios hecha después de 1988 y sobre los debates en la sociedad civil con relación a nuevas propuestas, el artículo hace una reflexión sobre el vacío legislativo en el cual Brasil vivió y sobre la ausencia de debate sobre el tema. 


\section{La protección compleja de derechos frente a los medios}

Las más conocidas normas de protección en las comunicaciones entre las personas ponen énfasis en la cuestión de la libertad individual. Son normas que protegen derechos como la libertad de expresión, libertad de prensa, libertad de religión y libertad de enseñanza. Esto queda claro después de una mirada sobre el proceso de construcción del Estado moderno, que es acompañado de la reafirmación de los derechos humanos. Esas libertades están en el inventario de instrumentos protectores, que se encontraban en los primeros documentos que consagraban los derechos (Machado, 2002).

En su origen, las libertades fundamentales fueron presentadas como protecciones contra el Estado naciente. Al mismo tiempo que la autoridad política estaba siendo legitimada, con ciertas funciones, ella era considerada peligrosa. El Estado era una especie de "mal necesario" para el constitucionalismo liberal, pues asumía la garantía de la administración de la justicia y la seguridad pública, pero era una amenaza a la libertad del individuo.

En la comunicación social, el riesgo mayor identificado en esa época era que el Estado resolviera utilizar sus poderes para prohibir la emisión de discursos específicos. El fantasma de la censura asombró a la prensa desde su nacimiento y en buena parte de su historia. En realidad, aún asombra, a pesar de tanta experiencia acumulada en la contención de los impulsos de la autoridad pública en democracias constitucionales. No obstante, hace mucho tiempo que ya no es posible restringir la reflexión sobre la relación entre el derecho y los medios de comunicación en torno al problema de la garantía de la libertad individual. Por supuesto, como ya se ha dicho, este problema no ha sido superado y la amenaza de la censura siempre persistirá. Siempre habrá el riesgo de que el uso excesivo del poder se deslice hacia prácticas de censura. Sin embargo, sería inocente asumir siempre la postura que se soporta solo en la defensa de la garantía de tales libertades individuales, por desconocer el potencial ofensivo de otros poderes no estatales y las posibilidades protectoras del Estado.
Necesitamos considerar el hecho de que la libertad no es amenazada solo por el poder público. Los derechos fundamentales no son protecciones únicamente contra el Estado, sino protecciones contra el poder. La atención en el Estado, en el primer discurso del constitucionalismo moderno, tiene relación con el desproporcional poder que él representaba y, además, con la inexistencia en ese momento de medios privados tan fuertes como los que hoy conocemos nosotros. Hay, como veremos, diversas amenazas privadas a las libertades en la comunicación. Además de la cuestión de los riesgos provenientes de poderes no estatales, es importante, también, colocar en las democracias constitucionales el problema de la protección de la igualdad, del equilibrio en la democracia, entre los diversos discursos en disputa.

Desde los orígenes clásicos de la experiencia democrática, se consideraba, por ejemplo, el problema de la asimetría entre los hablantes. En la democracia ateniense, había un principio de garantía de igualdad de habla en la asamblea. En dicha democracia-que conocía exclusivamente el debate presencial- la asimetría en el poder de habla era, de hecho, vista como un problema (Miller, 2001).

Las revoluciones burguesas recuperaron la idea antigua de democracia, como gobierno del pueblo. Sin embargo, ante el desafío de deliberar en sociedades con un gran número de miembros, construyeron una forma específica de democracia: la democracia representativa. Como vemos, democracia y comunicación, en la experiencia inaugural ateniense, tenían vínculos fuertes. En una situación de contacto directo, personal, en la cual vivían los atenienses, sin existencia de lugares de habla con poderes distintos, ya existía una preocupación con garantía de la participación en el debate. En la nueva democracia, que la modernidad presenta, la cuestión de la comunicación comparece, nuevamente. Sin embargo, el problema es agravado. No estamos hablando ya de contacto personal, sino de medios de comunicación que profundizan la asimetría entre individuos, en especial, entre los que tienen y los que no tienen acceso a tales medios.

Entre los países que más se destacan en el proceso de formación del constitucionalismo, Inglaterra es también importante a la hora de reconocer 
el papel esencial de la libertad de prensa: lo hizo antes, a medida en que construía el gobierno representativo. El discurso "Areopagitica", de 1644, de John Milton, es reconocido como un importante acto en la formación de la idea de libertad de expresión que los modernos afirmaron.

En el nacimiento del Estado moderno, la comunicación era, principalmente, presencial. Sin embargo, cuando la comunicación es estrictamente de este modo, es posible cuestionar la igualdad de habla. Basta, por ejemplo, pensar en una situación en la que una multitud abuchea alguien e impide así que este hable. La comunicación es presencial, pero la suma de voces crea por sí sola una asimetría entre los agentes. A su vez, hay que decir que los medios de comunicación impresos eran, en los primeros momentos del Estado moderno, los únicos poderes no estatales que podrían representar alguna asimetría entre quienes los poseían y quienes no los poseían. Es evidente que con la invención de la prensa ya se produjo una asimetría y hubo un acrecimiento significativo en el problema de la igualdad en la comunicación. Sin embargo, con los medios complejos y de gran alcance que tenemos hoy, el problema es mucho más grave.

Con el surgimiento de la radio y la televisión, el impacto de los medios está substancialmente alterado. El alcance de esos nuevos medios va mucho más allá de los medios impresos, que, hasta entonces, eran los medios de comunicación de las masas. Comienza a existir una escandalosa asimetría entre quienes tienen y quienes no tiene acceso a los medios.

No hay nada equiparable al impacto que tuvo la invención de la radio y de la televisión, en cuanto a la igualdad en la comunicación. Estos medios tenían un alcance antes inimaginable y representaron un cambio que profundizó las desigualdades entre los hablantes. Estos medios planteaban, además, el problema de la limitación del espectro magnético radiofónico. Como se sabe, el espectro electromagnético es muy limitado, pues el número de canales posibles no es infinito. Ante la limitación del acceso a la propiedad de esos medios y el impacto que representaron, en muchos países fueron regulados o permanecieron, por mucho tiempo, exclusivamente en manos del Estado.
Hoy, se habla de una verdadera democracia mediática, en la que la imagen personal, construida a través de los medios de comunicación, sustituye el lenguaje clásico. Las campañas electorales se despolitizan tanto como las campañas publicitarias de cualquier otro producto lanzados en el mercado. Radio, televisión e internet son medios fundamentales para la creación de la imagen y la venta del candidato.

Es necesario, pues, cambiar la perspectiva a partir de la cual se ve la relación entre Estado y derechos fundamentales en la comunicación. Es necesario, además, discutir el problema de la igualdad entre los participantes en el debate y el pluralismo en la comunicación - pluralismos internos (equilibrio en la cobertura periodística, espacios para grupos diversos en la programación, etc.) y externos (no concentración de la propiedad de los medios, la existencia de radiodifusión pública)El Estado es llamado, entonces, a ser un regulador. Este necesita editar normas e inspeccionar abusos, para garantizar los derechos fundamentales de individuos y grupos que pueden ser amenazados por los poderes de los medios.

Eso es lo que el Sistema Interamericano de Derechos Humanos llama de "dimensión colectiva o social" de la libertad de expresión. La Relatoría Especial para la Libertad de Expresión de la Comisión Interamericana de Derechos Humanos estableció, con base en decisiones de los órganos que componen el sistema, que "la libertad de expresión es un medio para el intercambio de informaciones e ideas entre las personas y para la comunicación masiva entre los seres humanos, que implica tanto el derecho a comunicar a otros el propio punto de vista y las informaciones $u$ opiniones que se quieran, como el derecho de todos a recibir y conocer tales puntos de vista, informaciones, opiniones, relatos y noticias, libremente y sin interferencias que las distorsionen u obstaculicen. A este respecto, se ha precisado que para el ciudadano común es tan importante el conocimiento de la opinión ajena o la información de que disponen otros, como el derecho a difundir la propia" (CIDH, 2010).

Una cuestión que necesita una regulación del Estado es la propiedad de los medios. La prohibición de la concentración de la propiedad es 
una protección a la sociedad, pues evita la creación de superpoderes que pueden deformar los contenidos. La concentración de la propiedad en pocas manos es, en sí, un problema grave: aporta poderes desproporcionados a algunos y tiene impacto directo en el debate democrático, destruyendo las condiciones básicas para una decisión que pondere los diversos discursos en disputa (Baker, 2006).

Sin embargo, la llamada propiedad cruzada, o sea, la posibilidad de concentrar una empresa de medios de comunicación de diversos tipos, en formas diferentes, conlleva un problema aún más desafiante. Una estrategia que combina televisión, radio, periódicos, revistas y blogs, coordinada por una corporación, puede representar un poder desproporcionado para esta, que es poseedora de medios.

De ahí que la necesidad del establecimiento de reglas y de autoridades reguladoras atienda a los intereses de toda la sociedad. Pero los problemas que rodean la comunicación son especialmente graves, cuando consideramos a los grupos sociales minoritarios. Generalmente, además de invisibilizados por la actuación cotidiana de los medios, esos grupos son víctimas de discursos que fomentan el odio, otro problema grave que necesita ser enfrentado por la regulación.

Traigamos aquí la definición de "discurso del odio" adoptada por el Consejo de Europa: "cualquier forma de expresión que propague, incite, promueva o justifique el odio racial, la xenofobia, el antisemitismo y otras formas de odio basadas en la tolerancia, incluyendo la intolerancia manifestada mediante un nacionalismo o etnocentrismo agresivos, la discriminación y la hostilidad contra las minorías, los inmigrantes y las personas de origen inmigrante" (Apud Martin Sánchez, 2012, p. 2). El discurso del odio, por lo tanto, estigmatiza y puede estimular la violencia hacia varios grupos. En el mundo entero, hay preocupación con ese tipo de discurso. Los documentos internacionales de derechos humanos generalmente incluyen una advertencia sobre el discurso del odio cuando tratan la libertad de expresión.

\section{La compatibilidad entre autorregulación y heterorregulación}

Es usual el discurso político que deslegitima la regulación de la comunicación a través de un órgano estatal y aparece, en cambio, acompañado de la defensa de una autorregulación, como presunta forma de garantizar cierto grado de respeto a los derechos, sin riesgo de caer en un autoritarismo. Este argumento es muy común en el debate brasileño. En esta posición se evidencia una incompatibilidad entre las dos formas de regulación.

Con la autorregulación, los propios agentes se encargan de la fijación de normas y de su control. Normalmente, los agentes que actúan en el mismo sector crean una entidad, que será responsable de la regulación. Con ello, el Estado es alejado del acompañamiento directo de la actividad. Tal autorregulación tiene, empero, límites evidentes, pues la lógica comercial de las empresas que actúan en el sector inevitablemente se reflejará en los órganos reguladores por ellas creadas. La publicidad en Brasil es un ejemplo de ello. El Conar tiene una actuación efectiva, corrigiendo, en muchos casos, los excesos cometidos por agencias de publicidad. Sin embargo, hay también ejemplos de omisiones por parte del Conar. Podemos señalar como problemático el tratamiento dado a la publicidad dirigida a niños (Monteiro, 2012). La posición del órgano puede ser asociada directamente al interés de esas mismas agencias, que no quieren perder un importante mercado.

Autorregulación y heterorregulación pueden ser complementarias, si se dedican a viabilizar canales adecuados para la sociedad a la hora de garantizar sus derechos. Los gobiernos reguladores solo pueden actuar en caso de que los sistemas de autorregulación sean frágiles. Esa forma de regular se llama corregulación.

Augusto Santos Silva (2007), estudiando el modelo portugués, resumió las alternativas, en términos de regulación, y las razones enumeradas por los adversarios del sistema de regulación directamente a la opción de otros caminos. El autor 
citado caracteriza el sistema portugués como un sistema de heterorregulación pública, que apunta al pluralismo y la diversidad en el "mercado social de las ideas", y legitima políticamente al Estado, aunque independientemente del Gobierno, para que la regulación sea ejercida a partir de principios y valores constitucionales, desde el punto de vista del ciudadano (Silva, 2007). En este modelo, una entidad estructurada ante el Parlamento, bajo la ley aprobada por dos tercios de los parlamentarios, con poderes sancionadores, regula los medios.

Las visiones críticas al modelo defienden (Silva, 2007): la inexistencia de regulación, a través de la Judicatura, en los excesos, para que reinen las libertades de prensa y de empresa; la autorregulación de una entidad voluntariamente creada por los regulados, que daría garantías ante posibles excesos del Estado, y la corregulación, en la que existe, vía de regla, una actuación de autorregulación, mientras que los entes de heterorregulación se hacen responsables de superar las flaquezas de la autorregulación.

Nos parece preferible que la heterorregulación sea realizada por una entidad especialmente creada para esa finalidad y no diluida en entidades de la administración directa, que acumulan otras funciones. Es importante recordar que una regulación por agencia, especialmente creada para esa finalidad, no implica que se otorguen a ese ente poderes ilimitados. Por el contrario, esta sería una entidad creada para cumplir designios constitucionales y así estaría sometida a los límites fijados en la Constitución. Siempre existirá, cuando los regulados o los ciudadanos estén en desacuerdo con las normas o los actos editados en la regulación, el recurso al poder judicial, que tiene, en el sistema brasileño, amplios poderes para apartar posibles ilegalidades o inconstitucionalidades, ante el principio de la inviabilidad del control jurisdiccional.

\section{La "Constitución de la comunicación" en Brasil}

La Constitución de Brasil comprende un capítulo específico sobre las normas de la "comunicación social”. Esta división se encuentra en el Título VIII, que versa sobre el "Orden social". Sin embargo, no se completa en este título lo que hemos llamado de "constitución de la comunicación". La actividad de la comunicación social tiene incidencia en otras normas que se vinculan con otras secciones del texto constitucional, entre las que se destacan las normas comprendidas en el Título II: "De los derechos y garantías fundamentales".

La Constitución brasileña contiene todo el compendio de libertades asociadas a la comunicación. El artículo 5, direccionado principalmente a los derechos fundamentales de primera generación, prevé la libertad de manifestación del pensamiento, siendo vedado el anonimato (IV). Contempla, además, la garantía del derecho de respuesta proporcional al agravio, sin perjuicio de la indemnización debida (V). Habla este dispositivo también sobre el libre ejercicio de los cultos religiosos, así como de la protección a los lugares para dicho culto (VI). Incluye un precepto normativo que garantiza el derecho a la objeción de conciencia y prohíbe la privación de derechos por la recusa del cumplimiento de alguna obligación impuestas a todos, desde que, además, no exima de cumplir las prestaciones alternativas previstas en la ley (VIII). El artículo 5 prevé también que la expresión de la actividad intelectual, artística, científica y de comunicación sea libre e independiente de toda censura o licencia (IX). Garantiza el acceso a la información, resguardando el sigilo de la fuente, necesario para el ejercicio profesional (XIV). El mismo artículo trae, además, un conjunto de garantías para la intimidad, la privacidad, la honra y la imagen que tienen impacto en el ejercicio de la actividad de las comunicaciones. Aborda inclusive el sigilo de correspondencia y de las comunicaciones (XII), y la inviolabilidad del domicilio (XI).

Sin embargo, el capítulo destinado especialmente a la comunicación social es el que contiene las reglas que habilitan al Estado para actuar como ente regulador, con el fin de garantizar la protección frente a las amenazas provenientes de la comunicación, que van más allá del discurso liberal clásico, el cual habla apenas de libertades individuales. Podría decirse que, a partir de tales normas, existe un fundamento para una actividad 
legislativa que precisa, de forma lógica, la contemplación de todas las limitaciones derivadas de la consagración de aquellas prerrogativas anteriormente citadas.

El capítulo está conformado por cinco artículos, del 220 al 224. El enunciado legal del artículo 220 reitera la declaración de la libertad de expresión, en otros términos: "la manifestación del pensamiento, la creación, la expresión y la información, sobre cualquier forma, proceso o vehículo informativo no sufrirán ninguna restricción, según lo dispuesto en esta Constitución”. Es justificable que la constitución de un país que sale de un régimen dictatorial refuerce, en los dispositivos normativos distintos, las libertades básicas. En ese mismo sentido, los párrafos primero y segundo del artículo 220 fortalecen la garantía de la libertad de prensa y de prohibición, ante la censura previa. También el párrafo 6 puede estar incluido en esa relación de dispositivos que buscan ampliar la expresión, ya que la necesidad de autorización para la impresión de cualquier publicación no es necesaria.

El párrafo 3 contiene las reglas que versan sobre protección de la infancia y la juventud. Dispone que la ley federal regulará "las diversiones y los espectáculos públicos”, y el Poder Público informará sobre la naturaleza y la franja de edad para los cuales aquellos no están recomendados, así como los lugares y horarios inadecuados para su presentación (I). Contempla también que esta ley debe establecer los "medios legales", a través de los cuales las familias podrían protegerse de una programación incompatible con los principios constitucionales. El párrafo 4 aborda las restricciones a la publicidad referente al "tabaco, bebidas alcohólicas, agrotóxicos, medicamentos y terapias".

El Párrafo 5 merece ser desatacado, porque fundamenta la regulación constitucional sobre la propiedad de los medios de comunicación, ya que afirma que estos "no pueden, directa o indirectamente, ser objeto de monopolio u oligopolio". Se trata de un dispositivo amplio, que va más allá de los servicios públicos de radiodifusión, involucrando de esa manera la preocupación sobre la concentración de todos los tipos de medios de comunicación.
El artículo 221 declara los principios que deben ser tenidos en cuenta para la producción y programación de las emisoras de radio y televisión: la preferencia de los fines educativos, artísticos, culturales e informativos; la promoción de la cultura nacional y regional, así como el estímulo a la producción independiente que objetive su divulgación; la regionalización de la producción cultural, artística y periodística, conforme a los porcentajes establecidos en ley, y el respeto a los valores éticos y sociales de la persona y de la familia.

Es evidente que la compatibilidad de ese dispositivo declaratorio de principios con las normas declaratorias de libertades necesita estar formulada por una regulación infraconstitucional; posibles porcentajes, por ejemplo, sobre programas regionales en la radiodifusión o de producción independiente no están definidos en la Constitución.

El artículo 222 contiene las normas de garantía del mercado para los nacionales. Prohíbe, en ese sentido, la propiedad de empresas de comunicación encabezadas por extranjeros, aunque dicha propiedad sea permitida, apenas, a los brasileños naturalizados con un lapso mayor de diez años. Las personas jurídicas pueden tener, como máximo, el $30 \%$ del capital extranjero. Dice, además, que "la responsabilidad editorial y las actividades de selección y dirección de la programación vehiculada son privativas de los brasileños natos o naturalizados con más de diez años, en cualquier medio de comunicación social".

El artículo 223, por su parte, concede al poder ejecutivo el otorgamiento y la renovación de las concesiones en radiodifusión, aunque somete dicho acto al Congreso Nacional. La cancelación de la concesión vigente solo podrá ser hecha por medio de una decisión judicial. Aquel contempla, además, el plazo de duración de una concesión de diez años para la radio y quince para la televisión. El artículo trata también el "principio de la complementariedad de los sistemas privado, público y estatal", lo que indica que no es posible confundir las radios y televisoras públicas y estatales, pues las públicas son aquellas financiadas con sus recursos públicos, pero no son susceptibles de control directo por parte del gobernante de turno, teniendo 
que, de alguna forma, someterlas a los controles de la sociedad.

Finalmente, el artículo 224 crea un Consejo de Comunicación Social junto al Congreso Nacional. Este Consejo tiene una finalidad para el asesoramiento, en la materia, del Parlamento. Pero, a decir verdad, aquel no ha tenido, desde su creación en 1988, algún tipo de protagonismo en la regulación de la comunicación social.

Es menester, por último, mencionar que no hay un amplio estatuto legal de la radiodifusión que enfrente todas las cuestiones tratadas en el texto de la Constitución. Hay un verdadero desierto regulatorio. En ese contexto, todos pierden: usuarios y empresas actúan sin referentes estables.

\section{La otra cara de la moneda: la realidad del "mercado" de los medios}

Los grupos económicos dominantes que actúan en Brasil no permiten la concesión de un espacio para el surgimiento y crecimiento de nuevos actores mediáticos. La organización no gubernamental Reporteros sin Fronteras elaboró un informe del país brasileño, según el cual hay una concentración de medios de comunicación en manos de algunos emporios económico-familiares (2013). El periodo de la dictadura militar fue especialmente favorable para la expansión de tales grupos, especialmente el Grupo Globo, que mantuvo una fuerte colaboración con el régimen dictatorial y, por esta razón, fue beneficiario de este tipo de gobierno autoritario (Lins, 2010).

Un grave conflicto de concentración de la información se revela, además, con el fenómeno de la propiedad cruzada de medios. En este caso, el Grupo Globo actúa prácticamente en todos los mercados mediáticos, y tiene una evidente posición dominante dentro de muchos de ellos. Existen también otros grupos que actúan en diversos sectores, incluso algunos grupos regionales fuertes, como el Grupo RBS, que trabaja con periódicos, radios y emisoras de televisión (retransmitiendo la programación del Grupo Globo), en toda la región sur del Brasil.
Otro problema que presenta un impacto directo en la democracia es el gran número de políticos con canales propios de radio y televisión. En la Constituyente de 1987-1998, el entonces presidente, Sarney, utilizó la concesión de radios y televisoras como mecanismo de chantaje para garantizarse un mandato de cinco años; en consecuencia, varias licencias fueron otorgadas a los constituyentes y a sus respectivas familias. Después de esto, se propagó el endémico proceso de la promiscuidad entre políticos y empresas de comunicación, denominado por Venício Lima como el "coronelismo" electrónico" (2007).

Actualmente, la ausencia de unas reglas claras en la radiodifusión permitió también el crecimiento de la pauta de las iglesias evangélicas en los medios masivos (Bucci, 2011). Algunas de ellas pasaron a titularizar sus canales de radio y televisión. Otras, a base de la recaudación de millones de reales de sus feligreses, compraron todas las parrillas de la programación, transformando la televisión en templos reproductores de su poder. Esas iglesias, normalmente vinculadas a la corriente neopentecostal, también actúan organizadamente en las elecciones, presentando y apoyando a los candidatos.

El país no cuenta con una autoridad independiente que administre, por ejemplo, el uso del espectro electromagnético radiofónico. Algunas cuestiones técnicas son decididas por la Agencia Nacional de telecomunicaciones (Anatel). La ley que la creó (9.472 de 1997) establece que este órgano de la administración pública es el responsable de la administración del espectro electromagnético; sin embargo, le deja la franja dedicada a la radio difusión a la administración del poder ejecutivo, que se encargará del otorgamiento de las licencias de los canales. En ese sentido, no existe claridad

1 Se trata de una referencia al fenómeno político conocido como "coronelismo", que consistía en una práctica política local, en los pequeños municipios, caracterizada por el clientelismo y el imperativismo, verificada especialmente en la llamada "Primera República” (1889-1930). El término se origina en la época en la que el cargo de "coronel” de la Guardia Nacional era distribuido a los líderes locales, grandes terratenientes.

Los medios de comunicación entre la regulación y la libertad: 
con respecto a los criterios para este tipo de concesiones, así como tampoco para la renovación de licencias de radio y televisión. No existe un seguimiento transparente que permita establecer, tanto para los concesionarios como para la sociedad, el fundamento de la renovación o no de una licencia.

No hay una política de incentivo y apoyo técnico o financiero para la radiodifusión comunitaria. La legislación vigente es restrictiva, previendo un alcance corto para las radios comunitarias, así como también hay silencio respecto a la televisión comunitaria. La radio, efectivamente nacida en las comunidades organizadas, tiene mucha dificultad para obtener una licencia y el funcionamiento no autorizado sufre una fuerte represión.

La clasificación de los contenidos prevista en la Constitución fue reglamentada bajo una enorme resistencia por parte de las empresas que actúan en la radiodifusión. Hicieron una campaña abierta contra la reglamentación de la norma constitucional, acusando al Gobierno, en la época dirigido por Lula, de promover la censura. Al final de todo, el sistema que fue construido está basado en la autoclasificación, con la posibilidad de que, a posteriori, el Ministerio de Justicia exprese su discordancia respecto de la clasificación.

Existen también graves problemas con la publicidad. Hoy en día, la propaganda está totalmente regulada por una entidad creada por las propias agencias de publicidad. La autorregulación se ha mostrado excesivamente favorable a dichas compañías y resistente a los pleitos de la sociedad civil con relación a las pautas publicitarias que ofenden los derechos humanos. El más reciente episodio que revela justamente esto, surgió por una campaña publicitaria transmitida en la televisión, en la cual el órgano de autorregulación se hacía un auto elogio. La propaganda ironizaba sobre las denuncias de racismo o machismo, como si fuesen exageraciones ridículas.

\section{Una iniciativa contra el vacío legislativo}

El Foro Nacional por la Democratización de la Comunicación (FNDC) es un organismo instituido por un conjunto de entidades actuantes dentro de los movimientos sociales. Se creó en 1991, como una articulación entre entidades y fue institucionalizado en 1995. Sus objetivos son:

I. fomentar, a través de todas sus instancias y medios, la democratización de la comunicación; II. incentivar la máxima ampliación de las condiciones de acceso de todos los segmentos de la sociedad a la propiedad, pose y utilización de los medios de comunicación social. III. fomentar el desarrollo de la capacidad de generación de la información a todos los segmentos sociales; IV. favorecer una amplia participación de todos los sectores de la asociación en la formulación de políticas públicas de comunicaciones; V. estimular el desarrollo sobre las formas de control público sobre los medios de comunicación de masas como condición para orientar las decisivas determinaciones del contenido de estos medios en el desarrollo de la cultura y de la democracia en el país; VI. fomentar la capacitación de los ciudadanos para la lectura crítica de los medios de comunicación, en sus diversas modalidades, y para el debate de la estética, a partir de la comprensión del lenguaje y de los artificios allí empleados; VII. estimular la elaboración teórica, técnico-científica y política sobre las comunicaciones; VIII. estimular el desarrollo de los sistemas de comunicación y la inserción de estos en el contexto internacional objetivando la autonomía estratégica y la soberanía del país.

Ese frente de entidades inició un movimiento para construir y hacerle dirigir al Parlamento una propuesta de regulación de la comunicación. El movimiento tiene similitudes con la iniciativa que ha surgido en Argentina y colocó en la pauta legislativa el asunto de la regulación de los medios. Sin embargo, el país no goza de una coyuntura política adecuada para que la iniciativa se desarrolle. En este momento, hay una minuta de proyecto de ley de iniciativa popular, que está en la fase de recolección de firmas para ser dirigida posteriormente al Congreso Nacional.

En Brasil, la iniciativa legislativa popular está prevista en la Constitución, en el párrafo segundo del artículo 61, y establece que aquella "puede ser ejercida por medio de la presentación en la Cámara de los Diputados de un proyecto de ley suscrito por un mínimo porcentaje del electorado nacional, 
distribuido por lo menos en cinco Estados, con al menos tres décimos de porcentaje de los electores de cada uno de ellos". Como en las elecciones de 2012 había más de 140 millones de electores, la campaña tendrá que recolectar cerca de un millón y medio de firmas de votantes, regularmente inscritos en los registros de la Justicia Electoral.

El proyecto se aproxima más a la temática abarcada por la ley argentina, ya que apenas se trata de la radiodifusión y las tecnologías de la información. La ley boliviana trata también las telecomunicaciones (telefonía) y los servicios postales. La ley ecuatoriana alcanza, además, los medios impresos. Dicho proyecto está hecho, como las leyes de Argentina, Bolivia y Ecuador, a partir de una distribución del espectro electromagnético; sin embargo, no sigue las mismas fórmulas. Usa una clasificación de sistemas de radiodifusión prevista en la Constitución: público, privado y estatal. Garantiza el $33 \%$ del espectro para el sistema público, compuesto por entidades "creadas de forma participativa, a partir de la posibilidad de acceso a los ciudadanos y a sus estructuras dirigentes y sometidas a las reglas democráticas de gestión" y cuya "finalidad principal no sea la transmisión de actos de los poderes Ejecutivo, Legislativo y Judicial". Divide, además, el sistema público entre "emisoras de carácter público o asociativo-comunitario”, con un $50 \%$ de canales para cada tipo.

Este crea un Fondo Nacional de Comunicación Pública, que estaría formado por los recursos del presupuesto de la Nación, de los Estados y Municipios, por recursos tributarios específicos y por los valores pagados por las concesionarias privadas de radio y televisión. De este fondo, el $25 \%$ como mínimo sería destinado a las instituciones de carácter asociativo-comunitario. El objetivo será el de garantizarle a esa radiodifusión pública no gubernamental una fuente permanente de financiación. Crea también un Consejo Nacional de Políticas de Comunicación y un "defensor de los derechos del público". El Consejo es un órgano formulador de políticas públicas. El defensor es una especie de ombudsman, con funciones ejecutivas, de fiscalización y representación junto a las entidades públicas.
Ahora bien, aunque no crea una agencia reguladora, distribuye las responsabilidades por medio de actividades reguladoras entre dos agencias ya existentes: la Agencia Nacional de Telecomunicaciones (Anatel) y la Agencia Nacional de Cine (Ancine).

Entre otras cosas, posee reglas para combatir la concentración de medios. Como ya se dijo, la Constitución brasileña prohíbe el monopolio. Sin embargo, a la falta de una norma clara que trate de una forma global de la concentración, para definir monopolio, nuestra realidad es la de una peligrosa concentración (Marironi, 2015). Para cambiar esa realidad, el proyecto establece que el mismo grupo económico no podrá controlar directamente más de cinco emisoras en el territorio nacional. Prohíbe, además, la propiedad cruzada de medios, al establecer que "una prestadora no podrá obtener el otorgamiento para explotar servicios de comunicación social electrónico si ya explota otro servicio de comunicación social de igual modalidad en la misma localidad, si fuere una empresa periodística que publique periódico diario o incluso si mantuviese relaciones de control con empresas en estas condiciones". Contempla una excepción en ciudades con hasta por lo menos cien mil habitantes, en las cuales una empresa podrá tener una emisora y un periódico diario, "desde que uno de los vehículos de comunicación no esté entre los tres de mayor audiencia o tiraje". La excepción no alcanza, sin embargo, la televisión por cable. Prohíbe, incluso, el proyecto de la venta de licencias.

Otra característica importante que se debe mencionar es que aborda reglas sobre la regionalización de la programación e incentiva la producción independiente. Emisoras de una red deben tener como mínimo $30 \%$ de la programación, entre las 7 a. m. y las 12 p. m., con producción regional. Las emisoras locales necesitan tener como mínimo el $70 \%$ de la programación regional. La emisora de televisión, en horario triple A, necesita transmitir, como mínimo un $10 \%$ sobre contenidos hechos por una productora brasileña independiente y, de este contenido, el $50 \%$ hecho en el "área de mercado de la emisora".

El proyecto prohíbe que tanto iglesias como partidos políticos sean dueños de las emisoras de

Los medios de comunicación entre la regulación y la libertad: 
radio o canales de televisión. Este dispositivo es importante para combatir el crecimiento de la titularidad de canales por iglesias, el cual compromete el pluralismo religioso en el país. Este es un debate urgente en Brasil. Nuevas iglesias compran emisoras de radio y canales de televisión y los utilizan para expandirse. Peor que eso: los utilizan para interferir en los procesos político-electorales.

Este proyecto tiene también un conjunto de reglas sobre el contenido de la programación. Por ejemplo, veta la circulación, en la radiodifusión, del llamado "discurso de odio". Prohíbe la censura previa, pero permite la punición, a posteriori, de la emisora que haga lo citado a continuación:

Promueva la discriminación de género, étnica-racial, de clase social, por orientación sexual, religión o creencia, edad, condición física, regionalismo o país, o cualquier manifestación de intolerancia relativa a estos atributos, exceptuadas las declaraciones hechas por terceros en programas periodísticos u obras de dramaturgia; viole la intimidad, la vida privada, la honra y la imagen de las personas, exceptuados los casos de prevalencia del interés público; exponga a las personas en situaciones que, de alguna forma, redunden en el constreñimiento o humillación; incite a la violencia, exceptuadas las declaraciones hechas por terceros en programas periodísticos y las obras de dramaturgia; viole el principio de la presunción de inocencia; promueva el proselitismo político, a no ser que sea sobre el contenido periodístico y en el horario electoral y reservado a los partidos políticos.

Además, refuerza las reglas de protección de la infancia y de la juventud, tratando la clasificación indicativa de la programación. Ya tratamos en este texto esa clasificación. Ella orienta a los padres en cuanto a la compatibilidad entre los contenidos y la edad de los hijos. Así mismo, el proyecto incluye los deberes de las emisoras, respecto al contenido educativo de la programación. Más que cuidar para no traer contenidos ofensivos, las emisoras necesitan tener una programación adecuada.

El proyecto establece los límites máximos de publicidad en la programación. Se refiere también al "contenido comercial que debe estar claramente identificado como tal en el momento de su vinculación, y no podrá superar el $25 \%$ del tiempo de la programación". Prohíbe la publicidad del tabaco y de medicamentos y restringe la propaganda de bebidas alcohólicas y de alimentos perjudiciales a la salud o de bajo contenido nutricional. Prohíbe la publicidad dirigida a personas con menos de 12 años.

El proyecto contempla el derecho de respuesta. Innova en esa temática al abordar, además del derecho individual, el derecho colectivo de respuesta. Este es un tema no tratado en el sistema brasileño, desde que el STF consideró la "ley de prensa" hecha por la dictadura civil-militar como incompatible con la Constitución (Da Costa, 2014). Esa ley tenía un procedimiento para requerirse el derecho de respuesta y parámetros para que el poder judicial pudiera decidir.

Otro punto interesante del proyecto es la regulación del "derecho de antena" de las organizaciones de la sociedad. Hoy por hoy, los partidos políticos cuentan con un derecho de acceso al tiempo de exhibición, en radio y televisión, de sus programas. A cada año, son distribuidos, por criterios objetivos, los horarios en los cuales los partidos políticos presentan sus visiones. En el período electoral, hay un tiempo específico para los candidatos. El proyecto pretende ampliar ese derecho de acceso para que también comprenda las organizaciones representativas de la sociedad civil. Una mayor visibilidad del pluralismo que marca la sociedad añade madurez a la democracia.

Este proyecto de ley aprovecha muchas innovaciones de los recientes procesos políticos latinoamericanos y propone una regulación democrática, promotora de derechos, compatible con la Constitución. Desgraciadamente, a la medida que el debate político está distorsionado por los estigmas lanzados contra la regulación, no hay espacio para que se convierta en acto normativo. Sin embargo, sirve para iluminar el debate constitucional.

\section{Consideraciones finales}

Los diseños institucionales de las democracias necesitan considerar la importancia que para ellas tiene la comunicación. Además de la garantía de las libertades individuales, es necesario considerar 
los riesgos que representan los medios no regulados. La relación entre Estado y comunicación es compleja. Por un lado, el Estado puede convertirse en una amenaza a la expresión del pensamiento. Por otro lado, solo él tiene la fuerza necesaria para frenar abusos que pueden ser cometidos por grandes corporaciones que actúan en los mercados de medios. La regulación precisa hacerse con reglas claras. Además, la ejecución de tales reglas debe ser encabezada por autoridades con relativa independencia en relación con las autoridades gubernamentales y el mercado de medios.

La regulación constitucional de la comunicación en Brasil se considera lo suficientemente plena para fundamentar la construcción de una legislación específica sobre el tema abordado por este texto. Las materias como la concentración de la propiedad, la protección de la infancia, la regionalización de la programación de la radiodifusión y el control del discurso del odio no solo pueden tratarse en la ley, sino que también necesitan estar regulados, para poder así construir ciertas condiciones adecuadas dentro de un debate político amplio. El objetivo de la regulación debe ser la ampliación del número de voces y, en esa ampliación, la garantía del pluralismo. Los diversos problemas verificados en los diversos medios de comunicación necesitan respuestas adecuadas.

En Brasil, hay graves problemas de concentración de los medios de comunicación. También hay un frágil proceso de análisis de las concesiones públicas de canales, pues no son claros los parámetros utilizados para la renovación de los contratos.

Esta legislación que defendemos para regular el área debe estar diseñada de forma cautelosa, para que sean también contempladas las libertades constitucionalmente previstas y las garantías de esas libertades. La regulación debe considerar las amenazas que vienen tanto del Estado como del mercado. Deben evitarse los canales de control del contenido que, en contravía de las razones alegadas para regular, reduzcan las voces en el debate. También se debe tener cuidado con los usos políticamente destructivos que pueden resultar de esos medios de comunicación.
Aunque no estén marcados solo por avances, sino también por retrocesos, las experiencias de otros países de América Latina necesitan ser estudiadas y consideradas. Son países que comparten los mismos problemas y sufren las mismas consecuencias de los males que marcan sus medios de comunicación.

Evidentemente, hay riesgos de mala utilización de los poderes que son atribuidos a los órganos estatales responsables de la regulación, pero tales riesgos necesitan ser minimizados con dibujos institucionales que los sometan, en la medida de lo posible, al control por parte de la sociedad. Es mejor, sin embargo, correr tales riesgos, que justificar una omisión destructiva para la democracia.

\section{Referencias}

BBrasil. Tribunal Superior Electoral. Recuperado de http:// www.tse.jus.br/eleicoes/estatisticas/repositorio-de-dados-eleitorais

Bucci, E. (2011). A radiodifusão e a democracia no Brasil. In: SORJ, Bernardo. Meios de comunicação e democracia: além do Estado e do Mercado/Bernardo Sorj (organizador). Río de Janeiro: Centro Edelstein de Pesquisas Sociais.

Comisión Interamericana de Derechos Humanos (CIDH). (2009). Relatoría especial para la libertad de expresión. Marco jurídico interamericano sobre el derecho a la libertad de expresión. Recuperado de http://www.oas. org/es/cidh/expresion/docs/cd/sistema_interamericano_de_derechos_humanos/libro/contenido_mJIAS. html\#p17

Da Costa, T. M. (2014). Conteúdo e alcance da decisão do STF sobre a lei de imprensa na ADPF 130. Revista Direito GV, 10(1), 119-154.

FNDC. Para expressar a liberdade. Recuperado de http:// www.paraexpressaraliberdade.org.br/arquivos-nocms/plip_versao_final.pdf

Lima, V. (2007). As "brechas" legais do coronelismo eletrônico. Aurora: Revista de Arte, Mídia e Política. Puc-Sp, São Paulo, (1), 113-126.

Lins, C. E. (2010). Entre o pluralismo informativo, a censura judicial e o pragmatismo político. Rincón, Omar (org.). ¿Por qué nos odian tanto? Estado y medios de comunicación en América Latina. Bogotá: Friedrich Ebert Stiftung, 303-312. 
Machado, J. E. M. (2002). Liberdade de expressão: dimensões constitucionais da esfera pública no sistema social. Coimbra: Coimbra.

Marinoni, B. (2015). Concentração dos meios de comunicação de massa e o desafio da democratização da mídia no Brasil. São Paulo: Friedrich Ebert Stieftung.

Martín Sánchez, I. (2012). El discurso del ódio em el ámbito del Consejo de Europa. Revista General de Derecho Canónico y Derecho Eclesiástico del Estado, (28), 1-33.

Miller, J. (2001). Democratic characterizations of democracy: liberty's relationship to equality and speech in ancient Athens. History of Political Thought, 22(3), 400-417.

Monteiro, M. C. S. (2012). A autorregulamentação em questão: a legitimidade do CONAR e a participação da esfera pública na discussão da publicidade para a criança. Anais do XXXV Congresso Brasileiro de Ciências da Comunicação. Fortaleza (CE): Intercom.

Página 12. (2012). Argentina es un modelo. Buenos Aires, oct. 2012. Recuperado de http://www.pagina12.com. ar/diario/elpais/1-205669-2012-10-16.html

Pla, I. L. (2001). Medios de comunicación y democracia: realidad, cultura cívica y respuestas legales y políticas. Razón y palabra, (23).

Reporteros sin Fronteras. (2013). O país dos trinta Berlusconis: os desequilíbrios mediáticos do gigante sul-americano. RSF. Recuperado de https://rsf.org/es/ node $/ 23940$

Silva, A. (2007). A hetero-regulação dos meios de comunicação social. Comunicação e Sociedade, 11, 15-27. 